\title{
Psychological Characteristics of Lung Cancer Patients During the 2019 Novel Coronavirus Outbreak: A Cross-Sectional and Longitudinal Study Based on a Propensity Score-Matched Population
}

\section{Kai Qian}

First People's Hospital of Yunnan

Yi Deng

First People's Hospital of Yunnan

Yun Chen

First People's Hospital of Yunnan

Hao Peng

First People's Hospital of Yunnan

Li-Hong Jiang ( $\square$ doctorkyle@126.com )

First People's Hospital of Yunnan https://orcid.org/0000-0002-7750-1327

\section{Research Article}

Keywords: Psychological characteristics, Lung cancer, Corona Virus Disease 2019, Cross-sectional study

Posted Date: November 1st, 2021

DOI: https://doi.org/10.21203/rs.3.rs-932424/v1

License: () (i) This work is licensed under a Creative Commons Attribution 4.0 International License. Read Full License 


\section{Abstract}

Objective: This study sought to reveale the psychological characteristics of lung cancer patients at different time points of the COVID-19 epidemic.

Methods: This cross-sectional study used data from two different regional medical centers. 128 pairs of lung cancer (LC) patients and non-lung cancer subjects (NLC) were selected through propensity score matching (PSM) analysis. For the longitudinal study, the anxiety and distress state before and during the COVID-19 pandemic were surveyed through a dedicated questionnaire.

Results: A total of $135 \mathrm{LC}$ patients and 165 healthy individuals were included in this cross-sectional study. After PSM analysis, 128 pairs of LC patients and NLC were matched and compared in this analysis. During the uptrend period of COVID-19 epidemic, there were significant differences in anxiety between LC patients and NLC $(P=0.005)$. For $L C$ patients, the proportions of severe distress differed significantly between the uptrend and the decline period $(22.05 \%$ vs $11.90 \%, P=0.032)$. In two-way repeated ANOVA analysis, no significant main effect for group or group $\times$ condition interaction effect has been founded. The distress of LC patients is mainly manifested as worry. Logistic regression showed that gender (OR=41.48, 95\% Cl: 9.7417.97), age ( $\mathrm{OR}=0.20,95 \% \mathrm{Cl}: 0.08-0.50)$, and education level $(\mathrm{OR}=4.82,95 \% \mathrm{Cl}: 1.98-11.69)$ were correlated with "worry" and contributed significantly to the model.

Conclusions: This study revealed that lung cancer patients had significant anxiety and distress during the uptrend period of the COVID-19 epidemic. The distress states of LC patients mainly manifested as worry, which was associated with age, gender, and education level.

\section{Background}

In December, 2019, a novel coronavirus (2019-nCoV) outbreak of pneumonia emerged in Wuhan, China, and has subsequently garnered attention around the world[1]. On February 11, 2020, the WHO formally named the disease triggered by 2019-nCoV as Corona Virus Disease 2019 (COVID-19)[2]. Public health emergencies have an impact on public mental health[3]. This impact might evolve to include a broad range of public mental health concerns, including distress reactions (insomnia, anger, extreme fear of illness even in those not exposed), health risk behaviors (increased use of alcohol and tobacco, social isolation), mental health disorders (posttraumatic stress disorder, anxiety disorders, distress, somatization), and lowered perceived health[4]. Additionally, people's emotional responses to an epidemic are likely to include extreme fear and uncertainty[5]. Among these mental health problems, psychological distress and anxiety are the most common, and effective interventions might be an important approach to improve outcomes for large numbers of people[6].

Compared with healthy populations, LC patients have reported higher levels of anxiety and distress[7]. It has been demonstrated that a quick identification of distress and anxiety may lead to prompt treatment and consequently to better adherence to the oncologic plan[8, 9]. Therefore, scholars have recommended paying attention to the anxiety and distress status of lung cancer patients[10]. Additionally, understanding the 
mental health response after a public health emergency might help medical workers and communities prepare for a population's response to a disaster[11].

One of the barriers to the widespread adoption of psychological intervention is the current lack of knowledge regarding the potential adverse psychological impact of the COVID-19 outbreak on lung cancer patients. Therefore, the anxiety and distress status of lung cancer patients at different time points of COVID-19 should be evaluated.

Although most lung cancer patients in China are not infected with COVID-19, the epidemic situation may have a particular impact on the psychology of these patients. In this cross-sectional study, we used LC patients' data from two clinical centers to conduct a propensity matching analysis with NLC to identify the anxiety and distress changes of cancer patients during the COVID-19 epidemic.

\section{Methods}

\section{Study overview and setting}

We conducted a population-based, propensity score-matched cross-sectional and longitudinal study. For recruitment for the cross-sectional study, information was advertised online and through a dedicated questionnaire. For the longitudinal study, the anxiety and distress state before and during the COVID-19 pandemic were surveyed. As of February 24, 2020, a total of 135 LC patients and 165 non-lung cancer controls from two independent medical centers were included in the study. The study protocol was reviewed and approved by the Research Ethics Board of the First People's Hospital of Yunnan Province [reference no. 20200009], and written informed consent was obtained from all participants. The reporting of this study followed the Strengthening the Reporting of Observational Studies in Epidemiology (STROBE) statement (eTable 1).

\section{Subjects and recruitment}

The baseline data of primary LC patients were collected from November 2019 to December 2019 at the First People's Hospital of Yunnan Province (Kunming City, China) and Daping Hospital (Chongqing City, China) for another study (data not shown). Inclusion criteria were 1) lung cancer diagnosis (all kinds of pathological types); 2) no psychological illness or family history of it; 3 ) age $\geq 20$ years; and 4) ability to complete the questionnaire independently. The non-lung cancer subjects (NLC) were recruited from volunteers, and the exclusion criteria were 1) posttraumatic stress disorder, obsessive-compulsive disorder, or major depression; 2) current treatment with psychotropic medication; 3) age <20 years; 4) multiple chronic difficulties associated with learning and/or conduct problems; 5) any concurrent psychotherapy[12]. When COVID-19 has broken out in China, all of the participants were recruited again through email or phone for the present study.

\section{Propensity score matching analysis}

PSM analysis was used to minimize selection bias and balance variables. Propensity scores for all patients were estimated by a logistic regression model using age, gender, religion, income, and education level as 
covariates, since these factors may affect the psychological characteristics of LC patients[13-15]. A one-toone nearest-neighbor matching algorithm with a caliper of 0.2 and without replacement was used ${ }^{[16,17]}$. PSM analysis was performed using SPSS software (v24.0,).

\section{Instruments and measures}

State Anxiety Inventory (SAI). State anxiety is the temporary and changeable feeling induced by the arousal of the autonomic nervous system (e.g., how a person is feeling at the time of a perceived threat)[18]; the SAI measures this feeling using 20 items rated on a 4-point scale (1, "none"; 2, "mild"; 3, "moderate"; 4, "severe") [19]. Total SAl scores can range from 20 to 80 . SAI scores $\geq 44$ were considered severe anxiety[20]. Both LC patients and NLC completed the SAI.

Chinese Distress Thermometer and problem list. The distress thermometer (DT) is a screening tool recommended by the National Comprehensive Cancer Network (NCCN)[21]. Since there are racial differences in responses to the DT[22], the validated Chinese version of the DT (CDT) was used to screen patients' levels of distress ranging from 0 (no distress) to 10 (extreme distress)[23]. Patients were instructed to circle the number (0-10) that best described how much distress they had been experiencing recently. A score of 4/10 indicates clinically significant distress and warrants additional evaluation (NCCN, 2017). Analysis of the Chinese version indicated that a cut-off score of $4 / 10$ has a sensitivity rate of 0.80 and specificity of 0.70[24]. Unlike the SAI, the CDT was used to evaluate distress status for LC patients only[25].

The original problem list was developed by a Distress Management Guideline Panel of the NCCN and consists of 39 problems commonly experienced by cancer patients[26]. The Chinese version of the problem list was adapted from the NCCN and includes the original 39 problems plus 1 item, relationship with healthcare providers $[27,28]$. Patients were asked to mark "yes" or "no"' to indicate whether they had experienced each problem in the past week.

\section{Assessment schedule}

According to the epidemic data released by the Chinese Center for Disease Control and Prevention (http://www.chinacdc.cn/), the initial 23 days was the rapid uptrend period of the COVID-19 epidemic (cohort effects peaked around February 9); then the epidemic entered the decline period (Figure 1). Therefore, we conducted assessments on participants who were included in this study during the uptrend and decline periods (Figure 2).

\section{Statistical analysis}

The demographic and clinical characteristics, CDT score, SAI scores, and problems were described using frequencies, percentages, and measures of central tendency and dispersion. Problem totals were calculated by creating frequency scores for the number of items checked in each category. The SAl score was modeled as a count variable (ranging from 20 to 80). For within-group differences, a group time interaction was assessed using two-way repeated measures ANOVA with the outcome as dependent variable and group (LC and NLC) and time (Baseline, Uptrend period and Decline period) as independent variables (fixed effects) [29]. Bonferroni post hoc tests were used if interactions were detected. ESs were calculated using 
Hedge's $g$ for repeated measures. Effect size (ES) of $0.00-0.19,0.20-0.49,0.50-0.79$, and $\geq 0.80$ represented trivial, small, moderate, and large effects, respectively. Mean differences and their $95 \%$ confidence intervals were also calculated. Besides, we used Student's t-test to assess the difference in SAI scores between LC patients and NLC, and a Mann-Whitney U test was performed for skew distribution. Pearson's chi-squared test was used to determine the proportion of severe anxiety (SAl scores $\geq 44$ ) and severe distress (CDT score $\geq 33$ ) at different time points of the COVID-19 outbreak.

Based on the frequency results, worry (yes vs no) was the most commonly endorsed emotional problem on the problem list in the uptrend and decline periods of COVID-19; logistic regression analyses with worry as the dependent variable were performed to test whether any demographic or clinical variables were the best predictors of worry.

Statistical analyses were performed with SPSS (version 23.4, IBM Corp., Armonk, NY) and GraphPad (version 8.3), with a two-sided $P<0.05$ considered statistically significant for all reports.

\section{Results}

\section{Demographic characteristics}

A total of 135 LC patients and 165 NLC were included in this cross-sectional study. The baseline characteristics of these demographics before and after PSM analysis are listed in Table 1. After PSM analysis, 128 pairs of LC patients and NLC were matched and compared in the subsequent analysis. The median age of the LC patients and NLC was 59.3 years (range, 29-77 years) and 59.7 years (range, 27-77 years), respectively. There were more males $(60.9 \%)$ than females $(39.1 \%)$ among the LC patients after PSM, while the NLC group had a slightly higher proportion of female patients. All variables were balanced between two groups after PSM analysis (Table 1).

\section{Anxiety at different time points of the COVID-19 outbreak}

Descriptive statistics for the anxiety of LC and NLC in the uptrend period are listed in Table 2. In the uptrend period of COVID-19, there were significant differences in SAI scores between LC patients and NLC $(P=0.000)$, while in the baseline and decline periods, there were no significant differences $(P=0.731$ and $P=0.102$, respectively) (Table 2). There was a significant difference in the prevalence of severe anxiety between LC patients and NLC in the uptrend period only ( $23.62 \%$ vs $10.32 \%, P=0.005$, eTable 1$)$. However, there was no significant difference in the proportion of severe anxiety (SAI scores $\geq 44$ ) between the uptrend period and the decline period $(23.62 \%$ vs $16.67 \%, P=0.168$, eTable 2$)$.

In two-way repeated ANOVA analysis (table 3), we did not find a significant main effect for the group $(p=0.356)$ or group $\times$ condition interaction effect $(p=0.151)$. There was a significant main effect for condition $(p=0.013 ; E S=0.15)$. We did not find a significant correlation coefficient $(p=0.378 ; r=-0.18)$ between diagnosis and the absolute change in anxiety. (Figure 3)

\section{Distress at different time points of the COVID-19 outbreak}


The distress of LC patients was significantly higher than the baseline in the uptrend period and the decline period. The proportions of severe distress $(C T D \geq 4)$ differed significantly between the uptrend period and the decline period $(22.05 \%$ vs $11.90 \%, P=0.032)$ (eTable 2 ).

In two-way repeated ANOVA analysis (table 3 ), we did not find a significant main effect for group $(p=0.757)$ or group $\times$ condition interaction effect ( $p>0.842)$ in any of the analyzed outcomes for distress. For all outcomes, there was not a significant main effect for condition $(p>0.05, E S=0.28)$ (Figure 3 )

\section{The problem list for LC patients in different periods of COVID-19}

All patients who completed the questionnaire survey $(n=127)$ reported at least one problem on the problem list. Different categories of problems were reported in different periods of COVID-19. During the uptrend period of COVID-19, the top five most frequent problems reported by all participants were worry $(n=51$, $40.2 \%)$, nervousness $(n=21,16.5 \%)$, and sleep $(n=18,14.2 \%)$, financial $(n=12,9.4 \%)$, and breathing $(n=9$, $7.1 \%$ ) problems. In the decline period of COVID19, the top five most frequent problems reported by all participants were worry $(n=49,38.9 \%)$, sleep $(n=22,17.5 \%)$, nervousness $(n=17,13.5 \%)$, financial problems $(n=11,8.7 \%)$, and constipation ( $n=10,7.9 \%)$. (eTable 3 and Figure 2$)$

\section{Logistic regression analysis}

With "worry" (yes vs no) as the dependent variable, age, gender, religion, education, income, and LC stage were entered into the analysis. The model predicted the correct value in $54.3 \%$ of cases. Gender ( $O R=41.48$, 95\% Cl: 9.74-17.97), age (OR=0.20, 95\% Cl: 0.08-0.50), and education level (OR=4.82, 95\% Cl: 1.98-11.69) were correlated with worry indicated on the emotional problem list and contributed significantly to the model. (Table 4).

\section{Discussion}

To the best of our knowledge, the present study is the first to examine the psychological characteristics of lung cancer patients during the COVID-19 outbreak. COVID-19 is causing mental health problems such as stress, anxiety, depressive symptoms, insomnia, denial, anger, and fear[1]. These mental health problems not only affect healthy people but could also affect lung cancer patients, who have been found to be more vulnerable than healthy populations[10,30]. Lung cancer survivors have been shown to experience elevated distress compared with survivors of other cancer types[31], and emotional difficulties in cancer survivors are directly associated with lower QoL and greater symptom burden[32]. Although psychologists and the government have called for more psychological counseling during the epidemic, insufficient psychological attention has been paid to patients with lung cancer. The prerequisite for this psychological counseling is to clarify the psychological characteristics of lung cancer patients during this epidemic.

We found that there was a difference in distress levels between NLC and LC patients. The distress level among the patients in our study was comparable with other studies on lung cancer patients[33, 34]. Distress reflects the spectrum of psychological problems (i.e., cognitive, emotional, social, and spiritual) associated with a diagnosis and treatment of cancer and can be measured by the CDT [35]. The NCCN published the 
first distress screening guidelines in the United States in 1999 (updated in 2017), recommending distress screening as a part of routine cancer care. According to previous reports, distress has prognostic value for lung cancer patients[36]. Our study further confirmed that the distress level of LC patients was higher than baseline during the COVID-19 epidemic, although this cross-sectional study could not reveal the long-term impacts on these patients. An explanation for this observation could be that lung cancer patients suffer from dual psychological distress from lung cancer and the COVID-19 epidemic.

With an improved understanding of the impact of demographic or disease characteristics on distress, the psychological intervention can be executed for LC patients in the COVID-19 outbreak period. Logistic regression showed that gender, age, and education level were correlated with "worry," which may be the main source of distress during the outbreak. In general, older people and males constitute a large proportion of lung cancer patients, which may explain the relationship between age and gender with worry. Additionally, LC patients with a higher education level usually have a better understanding of lung cancer and COVIP-19, which may explain the negative correlation of education level with worry.

During different periods of the epidemic, the lung cancer patients had different CTD scores. In the uptrend period of COVID-19, overwhelming and sensational news headlines and images added anxiety and fear about this situation as well as fostering rumors and hype to fill in the absence of information[4]. By contrast, in the decline period of the epidemic, LC patients' worries about the epidemic gradually diminished, while their concern about lung cancer may not be alleviated. Therefore, the DS showed a significant decrease in the decline period compared with the uptrend period of COVID-19, but it was still higher than at baseline.

Two validated anxiety measures are commonly used for lung cancer patients, the SAI and the Medical Outcomes Study Short-Form 36-item survey (SF-36)[37]. Since LC patients were matched with NLC in this study, the SAI was used to evaluate anxiety. There was a significant difference between LC and NLC during the uptrend period of COVID-19, while there was no difference between LC and NLC at baseline or in the decline period. We believe that the difference in the anxiety of lung cancer patients in the uptrend period was mainly due to the impact of the epidemic situation. Due to the gradual mitigation of the epidemic in the decline period, there was no significant difference in SAI scores between LC patients and NLC.

Some limitations of this study should be noted. First, as we write this paper, the COVID-19 epidemic is slowly evolving in China. Although this cross-sectional study included the uptrend and decline periods, the design and results did not capture the changing patterns of psychosocial distress over the entire COVID-19 outbreak. Nevertheless, we can more or less predict the expected mental/physical health consequences and most vulnerable populations. Second, given the use of previous baseline data, the included patients represent a population with lung cancer only. This selection bias likely contributed to the limitations of tumor type selection of this study. For future studies, it might be of interest to include a broader sample and other types of tumor patients. Third, PSM accounts only for observed covariates. Factors that affect assignment to treatment and outcome but that cannot be observed cannot be accounted for in the matching procedure. As the procedure only controls for observed variables, any hidden bias due to latent variables may remain after matching. Moreover, the longitudinal study has a limited sample size. Finally, the Chongqing and 
Yunnan was not the central area of the COVID-19 outbreak; nevertheless, as of February 20, 2020, 567 and 236 patients in Chongqing and Yunnan were diagnosed with COVID-19 respectively.

\section{Conclusions}

As far as we knew, this is the first study reveals that compared with non-lung cancer people, lung cancer patients experienced significantly higher anxiety and distress during the uptrend period of the COVID-19 epidemic. In addition, during the uptrend period of COVID-19, LC patients showed more obvious distress than NLC, and this distress mainly manifested as worry, which was associated with age, gender, and education level. Further study of efficacy and underlying mechanisms is warranted.

\section{Abbreviations}

COVID-19: Corona Virus Disease 2019; 2019-nCoV: 2019 novel coronavirus; LC: lung cancer; NLC: Non-lung cancer subjects; STROBE: Strengthening the Reporting of Observational Studies in Epidemiology; PSM: Propensity score matching; DT: distress thermometer score; DS: distress scores; SAl: State Anxiety Inventory; CDT: Chinese Distress Thermometer score; NCCN: National Comprehensive Cancer Network; SAl: State Anxiety Inventory, Cl: confidence interval, ES: effect size

\section{Declarations}

\section{Acknowledgments}

We thank the all patients, the clinical staff who are providing care for the patient, and all the people who fight with COVID-19.

\section{Authors' contributions}

Conception and design: LHJ, KQ, YD; Administrative support: HP; Data extraction: YD, YC凶KQ; Collection and assembly of data: KQ, YC,YD; Data analysis and interpretation: YC囚HP, YD; Manuscript writing: All authors; Final approval of manuscript: All authors.

\section{Funding}

This study is supported by the Technology Innovation and Application Development Project of Chongqing Province (Project Reference Number: cstc2019jscx-msxmX0233). The funds supported the design of the study and collection, analysis, and interpretation of data.

\section{Availability of data and materials}

The datasets generated and/or analyzed during the current study are not publicly available because the file contains personal or clinical details of participants that compromise anonymity, but are available from the corresponding author on reasonable request. 
This study was reviewed and approved by the ethics committee of The First People's Hospital of Yunnan Province [reference no. 20200009]

Consent for publication

All authors and patients involved in this article agree to publish this article on BMC Psychiatry. (consent form can be provided at any time if needed.)

Competing interests

The authors declare that they have no competing interests.

\section{References}

1. Kang L, Li Y, Hu S, Chen M, Yang C, Yang BX, Wang Y, Hu J, Lai J, Ma X et al: The mental health of medical workers in Wuhan, China dealing with the 2019 novel coronavirus. Lancet Psychiatry 2020.

2. Guan WJ, Ni ZY, Hu Y, Liang WH, Ou CQ, He JX, Liu L, Shan H, Lei CL, Hui DSC et al: Clinical Characteristics of Coronavirus Disease 2019 in China. N Engl J Med 2020.

3. Thornicroft G, Farrelly S, Szmukler G, Birchwood M, Waheed W, Flach C, Barrett B, Byford S, Henderson $\mathrm{C}$, Sutherby K et al: Clinical outcomes of Joint Crisis Plans to reduce compulsory treatment for people with psychosis: a randomised controlled trial. Lancet 2013, 381(9878):1634-1641.

4. Shigemura J, Ursano RJ, Morganstein JC, Kurosawa M, Benedek DM: Public responses to the novel 2019 coronavirus (2019-nCoV) in Japan: mental health consequences and target populations. Psychiatry Clin Neurosci 2020.

5. Gill G, Burrell S, Brown J: Fear and frustration-the Liverpool cholera riots of 1832. Lancet 2001, 358(9277):233-237.

6. Matcham F, Rayner L, Hutton J, Monk A, Steel C, Hotopf M: Self-help interventions for symptoms of depression, anxiety and psychological distress in patients with physical illnesses: a systematic review and meta-analysis. Clin Psychol Rev 2014, 34(2):141-157.

7. Chad-Friedman E, Coleman S, Traeger LN, Pirl WF, Goldman R, Atlas SJ, Park ER: Psychological distress associated with cancer screening: A systematic review. Cancer 2017, 123(20):3882-3894.

8. Monfredo M, Mordenti P, di Nunzio C, Citterio C, Cavanna L: The thermometer of distress in oncology. Ann Oncol 2017, 28 Suppl 6:vi84.

9. Nelson CJ, Weinberger MI, Balk E, Holland J, Breitbart W, Roth AJ: The chronology of distress, anxiety, and depression in older prostate cancer patients. Oncologist 2009, 14(9):891-899.

10. Haun MW, Sklenarova H, Villalobos M, Thomas M, Brechtel A, Lowe B, Herzog W, Hartmann M:

Depression, anxiety and disease-related distress in couples affected by advanced lung cancer. Lung Cancer 2014, 86(2):274-280.

11. von Keudell A, Koh KA, Shah SB, Harris MB, Smith M, Rodriguez EK, Dyer G: Mental health after the Boston marathon bombing. Lancet Psychiatry 2016, 3(9):802-804. 
12. Eldar S, Apter A, Lotan D, Edgar KP, Naim R, Fox NA, Pine DS, Bar-Haim Y: Attention bias modification treatment for pediatric anxiety disorders: a randomized controlled trial. Am J Psychiatry 2012, 169(2):213-220.

13. Shimizu K, Nakaya N, Saito-Nakaya K, Akechi T, Yamada Y, Fujimori M, Ogawa A, Fujisawa D, Goto K, Iwasaki $\mathrm{M}$ et al: Clinical biopsychosocial risk factors for depression in lung cancer patients: a comprehensive analysis using data from the Lung Cancer Database Project. Ann Onco/2012, 23(8):1973-1979.

14. van Montfort E, de Vries J, Arts R, Aerts JG, Kloover JS, Traa MJ: The relation between psychological profiles and quality of life in patients with lung cancer. Support Care Cancer 2020, 28(3):1359-1367.

15. Shimizu K, Nakaya N, Saito-Nakaya K, Akechi T, Ogawa A, Fujisawa D, Sone T, Yoshiuchi K, Goto K, Iwasaki $\mathrm{M}$ et al: Personality traits and coping styles explain anxiety in lung cancer patients to a greater extent than other factors. Jpn J Clin Oncol 2015, 45(5):456-463.

16. He C, Wang J, Sun S, Zhang Y, Lin X, Lao X, Cui B, Li S: Irreversible electroporation versus radiotherapy after induction chemotherapy on survival in patients with locally advanced pancreatic cancer: a propensity score analysis. BMC Cancer 2019, 19(1):394.

17. Austin PC: Optimal caliper widths for propensity-score matching when estimating differences in means and differences in proportions in observational studies. Pharm Stat 2011, 10(2):150-161.

18. Gros DF, Simms LJ, Antony MM: Psychometric properties of the state-trait inventory for cognitive and somatic anxiety (STICSA) in friendship dyads. Behav Ther 2010, 41(3):277-284.

19. Qian K, Feng YG, Zhou JH, Wang RW, Tan QY, Deng B: Anxiety after Sympathectomy in patients with primary palmar hyperhidrosis may prolong the duration of compensatory hyperhidrosis. $J$ Cardiothorac Surg 2018, 13(1):54.

20. Swanson AJ, Castel LD, McKenna PA, Shen YA, Sagar B: Integration of the National Comprehensive Cancer Network (NCCN) Distress Screening Tool as a Guidepost for Telephonic Oncology Case Management. Prof Case Manag 2019, 24(3):148-154.

21. Donovan KA, Deshields TL, Corbett C, Riba MB: Update on the Implementation of NCCN Guidelines for Distress Management by NCCN Member Institutions. J Natl Compr Canc Netw 2019, 17(10):1251-1256.

22. McDonagh PR, Slade AN, Anderson J, Burton W, Fields EC: Racial differences in responses to the NCCN Distress Thermometer and Problem List: Evidence from a radiation oncology clinic. Psychooncology 2018, 27(10):2513-2516.

23. Tan H, Chen S, Ercolano E, Lazenby M, Davies M, Chen J, McCorkle R: The prevalence and related factors associated with psychosocial distress among $\mathbf{4 2 0}$ hospitalised lung cancer patients in China: A case study. Eur J Cancer Care (Engl) 2019, 28(4):e13046.

24. Tang LL, Zhang YN, Pang Y, Zhang HW, Song LL: Validation and reliability of distress thermometer in chinese cancer patients. Chin J Cancer Res 2011, 23(1):54-58.

25. Schellekens MPJ, van den Hurk DGM, Prins JB, Molema J, van der Drift MA, Speckens AEM: The suitability of the Hospital Anxiety and Depression Scale, Distress Thermometer and other instruments to screen for psychiatric disorders in both lung cancer patients and their partners. J Affect Disord 2016, 203:176-183. 
26. Donovan KA, Jacobsen PB: Progress in the implementation of NCCN guidelines for distress management by member institutions. J Natl Compr Canc Netw 2013, 11(2):223-226.

27. Zheng B, Du P, Yi T, Liu J, Zeng Z, Luo D, Jiang Y: Effects of two translated phrases of distress thermometer on screening distress in Chinese cancer patients: A comparative study. J Clin Nurs 2019, 28(5-6):828-835.

28. Chiou YJ, Chiu NM, Wang LJ, Li SH, Lee CY, Wu MK, Chen CC, Wu YS, Lee Y: Prevalence and related factors of psychological distress among cancer inpatients using routine Distress Thermometer and Chinese Health Questionnaire screening. Neuropsychiatr Dis Treat 2016, 12:2765-2773.

29. Pilmark NS, Lyngbaek M, Oberholzer L, Elkjaer I, Petersen-Bonding C, Kofoed K, Siebenmann C, Kellenberger K, van Hall G, Abildgaard $\mathrm{J}$ et al: The interaction between metformin and physical activity on postprandial glucose and glucose kinetics: a randomised, clinical trial. Diabetologia 2020.

30. Wang B, Hao N, Zhang X: Factors influencing the psychology and quality of life in lung cancer patients. Saudi Med J 2017, 38(9):948-951.

31. Sugimura H, Yang P: Long-term survivorship in lung cancer: a review. Chest 2006, 129(4):1088-1097.

32. Morrison EJ, Novotny PJ, Sloan JA, Yang P, Patten CA, Ruddy KJ, Clark MM: Emotional Problems, Quality of Life, and Symptom Burden in Patients With Lung Cancer. Clin Lung Cancer 2017, 18(5):497503.

33. Schofield P, Ugalde A, Gough K, Reece J, Krishnasamy M, Carey M, Ball D, Aranda S: A tailored, supportive care intervention using systematic assessment designed for people with inoperable lung cancer: a randomised controlled trial. Psychooncology 2013, 22(11):2445-2453.

34. de Mol M, den Oudsten BL, Aarts M, Aerts J: The distress thermometer as a predictor for survival in stage III lung cancer patients treated with chemotherapy. Oncotarget 2017, 8(22):36743-36749.

35. Lazenby M, Tan H, Pasacreta N, Ercolano E, McCorkle R: The five steps of comprehensive psychosocial distress screening. Curr Oncol Rep 2015, 17(5):447.

36. Geerse OP, Brandenbarg D, Kerstjens HAM, Berendsen AJ, Duijts SFA, Burger H, Holtman GA, HoekstraWeebers J, Hiltermann TJN: The distress thermometer as a prognostic tool for one-year survival among patients with lung cancer. Lung Cancer 2019, 130:101-107.

37. Franceschini J, Santos AA, El Mouallem I, Jamnik S, Uehara C, Fernandes AL, Santoro IL: [Assessment of the quality of life of patients with lung cancer using the Medical Outcomes Study 36-item Short-Form Health Survey]. J Bras Pneumol 2008, 34(6):387-393.

\section{Tables}

Table 1 Demographic characteristics 


\begin{tabular}{|c|c|c|c|c|c|c|c|c|}
\hline \multirow[t]{2}{*}{ Characteristics } & \multicolumn{4}{|c|}{ Before PSM, $n$} & \multicolumn{4}{|c|}{ After PSM, $n$} \\
\hline & LC & NLC & Total number & $P$ value & LC & NLC & Total number & $P$-value \\
\hline Total number & 135 & 165 & 300 & & 128 & 128 & 256 & \\
\hline \multicolumn{9}{|l|}{ Age (years) } \\
\hline$<30$ & 4 & 13 & 17 & 0.017 & 4 & 5 & 12 & 0.898 \\
\hline $30-49$ & 28 & 30 & 58 & & 27 & 24 & 47 & \\
\hline $50-69$ & 73 & 66 & 139 & & 70 & 68 & 122 & \\
\hline$\geq 70$ & 30 & 56 & 86 & & 27 & 31 & 75 & \\
\hline \multicolumn{9}{|l|}{ Gender } \\
\hline Male & 85 & 78 & 172 & 0.007 & 78 & 75 & 153 & 0.702 \\
\hline Female & 50 & 87 & 128 & & 50 & 53 & 103 & \\
\hline \multicolumn{9}{|l|}{ Religion } \\
\hline Buddhism & 27 & 32 & 59 & 0.107 & 24 & 26 & 50 & 0.744 \\
\hline Christianity & 11 & 19 & 30 & & 10 & 11 & 24 & \\
\hline Catholicism & 14 & 6 & 20 & & 14 & 9 & 17 & \\
\hline Other & 83 & 108 & 191 & & 80 & 82 & 165 & \\
\hline \multicolumn{9}{|l|}{ Education } \\
\hline Elementary school & 65 & 54 & 144 & 0.008 & 62 & 60 & 122 & 0.860 \\
\hline High school & 42 & 79 & 96 & & 42 & 46 & 88 & \\
\hline University & 28 & 32 & 60 & & 24 & 22 & 46 & \\
\hline Income (RMB) & & & & 0.003 & & & & \\
\hline$<5,000$ & 54 & 94 & 125 & & 54 & 53 & 107 & 0.899 \\
\hline$\geq 5,000$ & 81 & 71 & 175 & & 74 & 75 & 149 & \\
\hline
\end{tabular}

Table 2 Descriptive statistics for anxiety measures at each time point 


\begin{tabular}{|c|c|c|c|c|c|c|c|c|c|}
\hline \multirow{2}{*}{$\begin{array}{l}\text { Time } \\
\text { Point } \\
\text { and } \\
\text { Subscale }\end{array}$} & \multirow{2}{*}{$\begin{array}{l}\text { Score } \\
\text { Range } \\
\text { of SAl }\end{array}$} & \multicolumn{3}{|l|}{ LC } & \multicolumn{3}{|l|}{ NLC } & \multirow{2}{*}{$\begin{array}{l}\text { Difference } \\
\text { in Mean }\end{array}$} & \multirow[t]{2}{*}{$P$-value } \\
\hline & & $N$ & $\begin{array}{l}\text { Mean/ } \\
\text { Median }\end{array}$ & $\begin{array}{l}S D / \\
\text { Quartiles }\end{array}$ & $N$ & $\begin{array}{l}\text { Mean/ } \\
\text { Median }\end{array}$ & $\begin{array}{l}S D / \\
\text { Quartiles }\end{array}$ & & \\
\hline Baseline & $\begin{array}{l}20- \\
80\end{array}$ & 128 & $28.51^{\#}$ & $8.27^{\#}$ & 128 & $24.95^{\#}$ & $5.30^{\#}$ & 3.56 & $0.731^{*}$ \\
\hline $\begin{array}{l}\text { Uptrend } \\
\text { period }\end{array}$ & $\begin{array}{l}20- \\
80\end{array}$ & 127 & $40.97^{\#}$ & $8.78^{\#}$ & 126 & $35.86^{\#}$ & $5.19^{\#}$ & 5.11 & 0.000 * \\
\hline $\begin{array}{l}\text { Decline } \\
\text { period }\end{array}$ & $\begin{array}{l}20- \\
80\end{array}$ & 126 & 34.18 & 7.26 & 126 & 32.79 & 6.12 & 1.39 & 0.102 \\
\hline
\end{tabular}

Note: SAl: State Anxiety Inventory, *Mann-Whitney U test, "SAI has a skew distribution median and quartiles instead.

Table 3 Results on the effects of time on the psychological characteristics

\begin{tabular}{|c|c|c|c|c|c|c|}
\hline Variable & $\begin{array}{l}\text { Main effect } \\
\text { for Group } \\
\text { p-value }\end{array}$ & $\begin{array}{l}\text { Main effect } \\
\text { for condition } \\
\text { p-value }\end{array}$ & $\begin{array}{l}\text { Groupxcondition } \\
\text { interaction effect } \\
\text { p-value }\end{array}$ & $\begin{array}{l}\text { ES for } \\
\text { condition } \\
\text { and } 95 \% \mathrm{Cl}\end{array}$ & $\begin{array}{l}\text { Mean } \\
\text { diff and } \\
95 \% \text { Cl* }\end{array}$ & $\begin{array}{l}\text { Correlation } \\
\text { p-value }\end{array}$ \\
\hline $\begin{array}{l}\text { SAI } \\
\text { score }\end{array}$ & 0.356 & 0.013 & 0.151 & $\begin{array}{l}0.15(0.03- \\
0.25)\end{array}$ & $\begin{array}{l}25.8 \\
(22.3- \\
35.9)\end{array}$ & 0.387 \\
\hline $\begin{array}{l}\text { CDT } \\
\text { score }\end{array}$ & 0.757 & 0.821 & 0.842 & $\begin{array}{l}0.28(0.09- \\
0.36)\end{array}$ & $\begin{array}{l}2.7(1.2- \\
4.3)\end{array}$ & 0.452 \\
\hline
\end{tabular}

Note: SAl: State Anxiety Inventory, Cl: confidence interval, CDT: the validated Chinese version of the distress thermometer, ES: effect size, *: mean difference between lung cancer patients and non-lung cancer people for the whole sample;

Table 4 Logistic regression of LC patients with dichotomized worry outcome in uptrend period of COVID-19 


\begin{tabular}{|lllll|}
\hline Variables & P-value & $\operatorname{Exp}(\mathrm{B})$ & \multicolumn{2}{c|}{$\mathbf{9 5 \%} \mathrm{Cl}$ for $\operatorname{Exp}(\mathrm{B})$} \\
\cline { 4 - 5 } & & & Lower & Upper \\
\hline Gender & $\mathbf{0 . 0 0 0}$ & 41.481 & 9.674 & 177.861 \\
\hline Religion & 0.908 & 0.973 & 0.608 & 1.556 \\
\hline Age & $\mathbf{0 . 0 0 1}$ & 0.201 & 0.080 & 0.501 \\
\hline Education & $\mathbf{0 . 0 0 1}$ & 4.816 & 1.984 & 11.691 \\
\hline Income & 0.247 & 1.970 & 0.624 & 6.213 \\
\hline Lung cancer stage* & 0.589 & 1.362 & 0.444 & 4.174 \\
\hline Age by gender & 0.060 & 0.874 & 0.759 & 1.006 \\
\hline Age by education & 0.335 & 0.934 & 0.813 & 1.073 \\
\hline Gender by education & 0.268 & 1.129 & 0.911 & 1.399 \\
\hline Constant & 0.099 & 0.025 & & \\
\hline
\end{tabular}

Note: *: Staging according to NCCN guidelines of lung cancer.

\section{Figures}

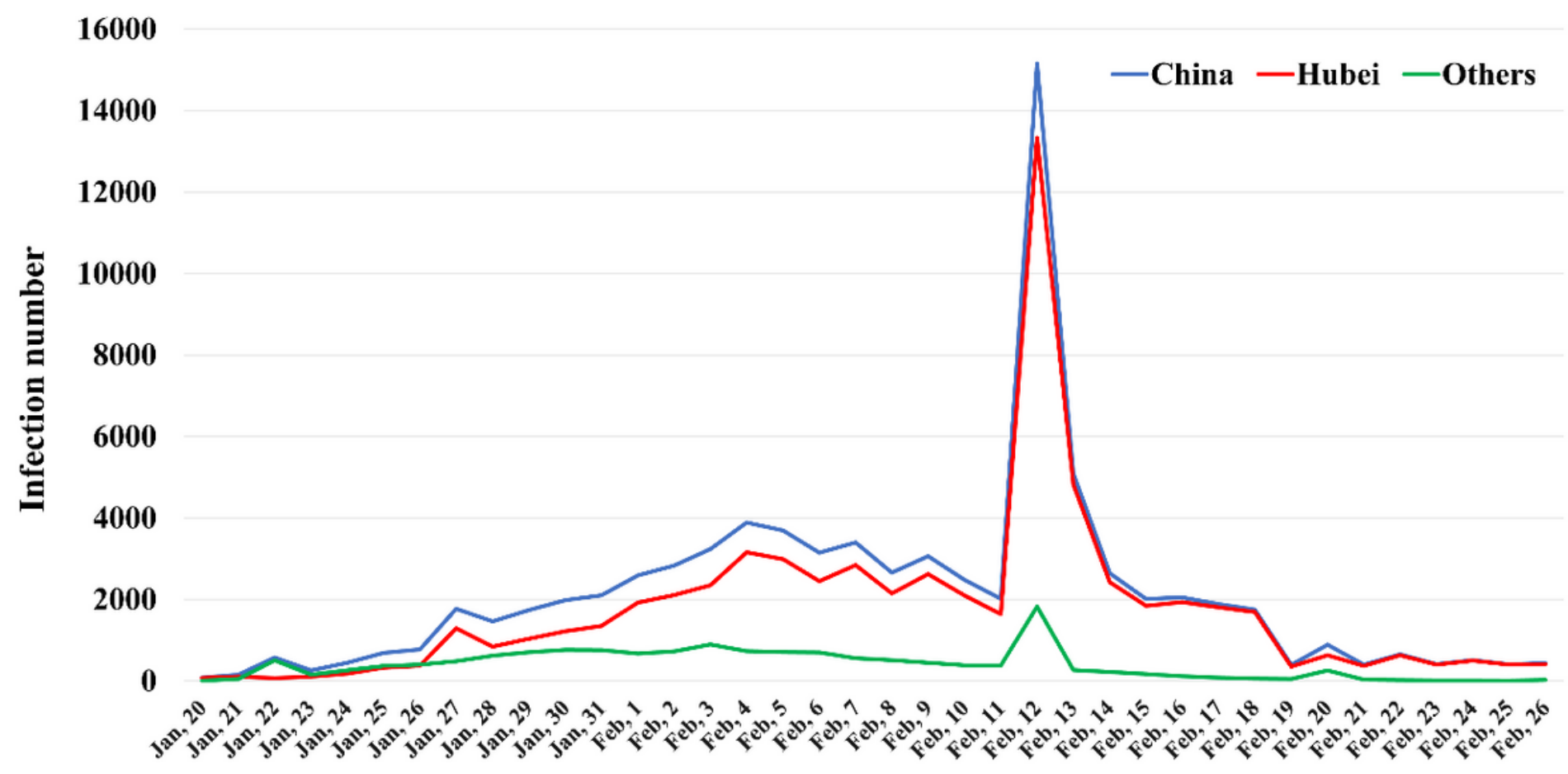

Figure 1 
COVID-19 trend chart in China. Blue line: The reported cases in China; red line: the reported cases in Hubei; green line: reported cases in other regions of China.

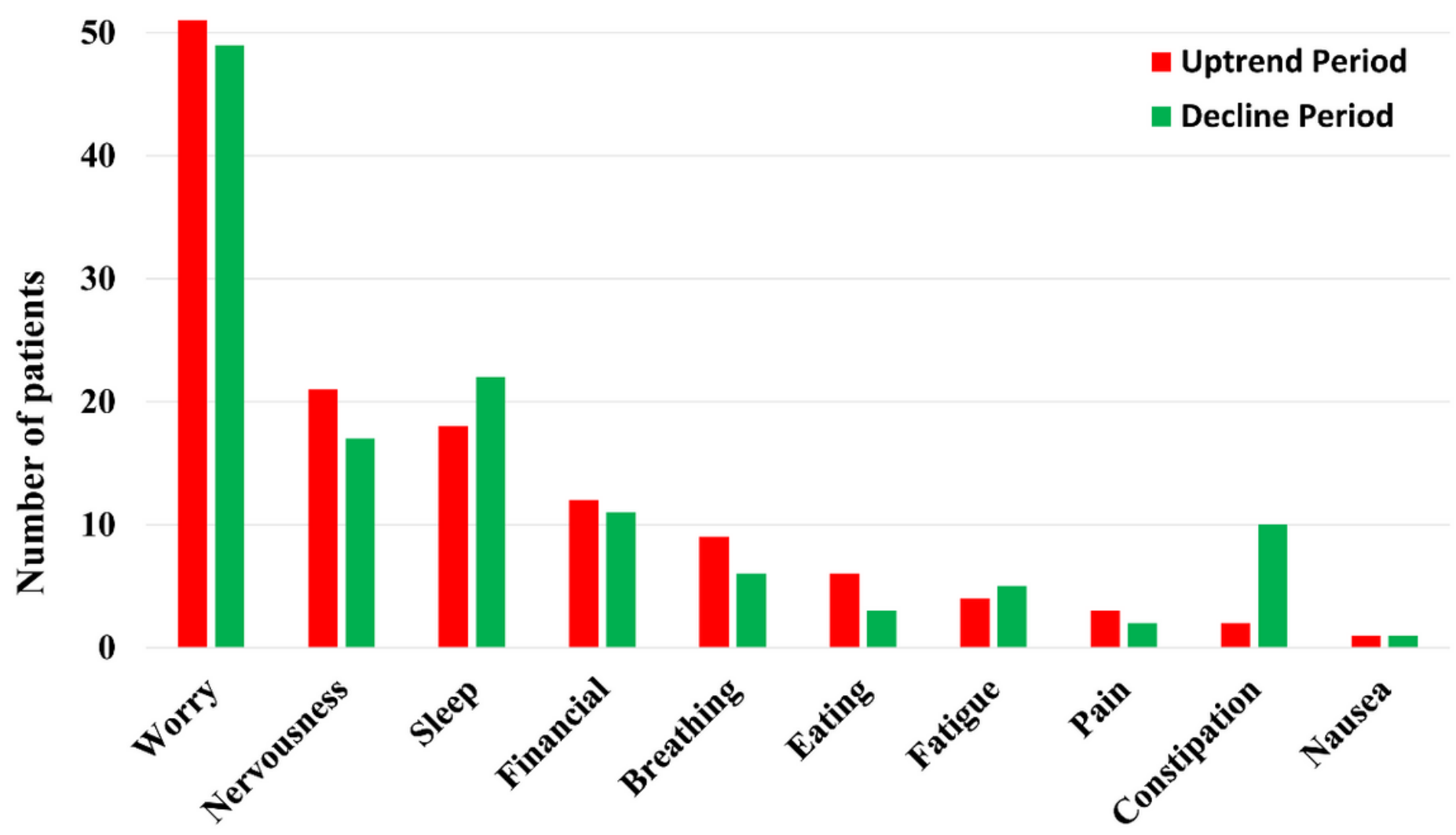

Figure 2

Patients' report of the top 10 problems from the CDT problem list during the uptrend and decline periods. 
A

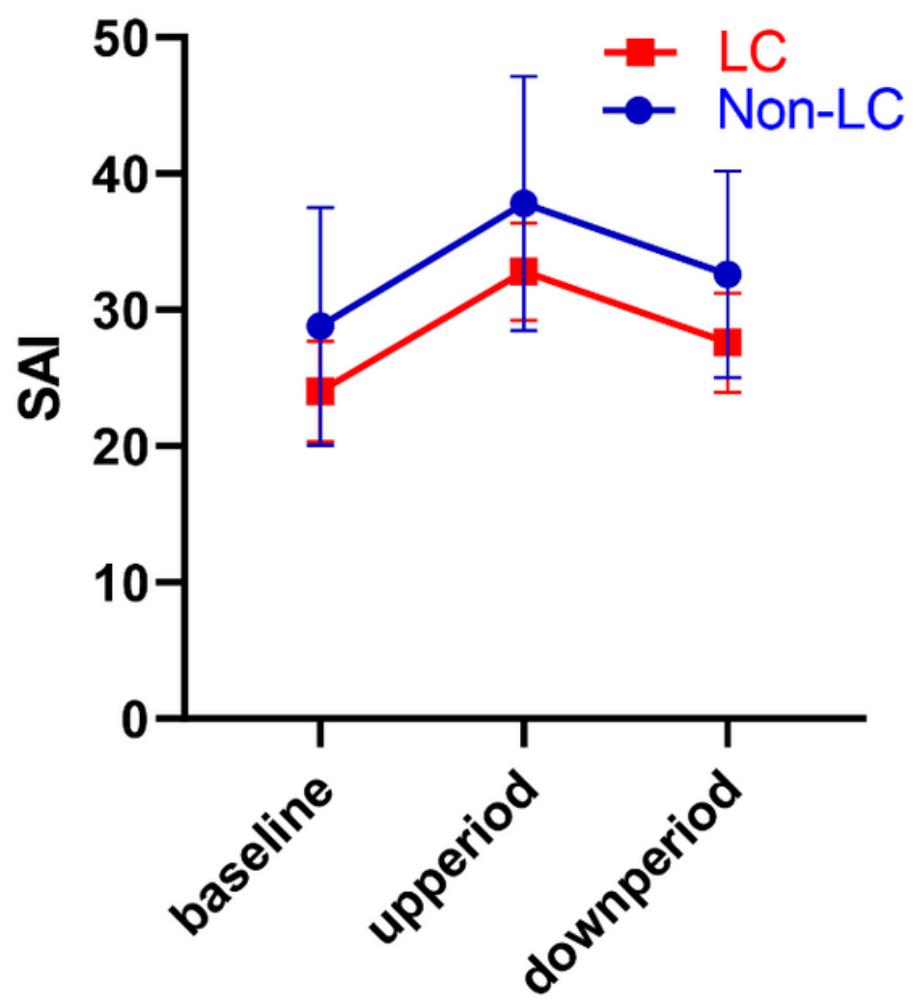

Time
B



Time

\section{Figure 3}

Psychological characteristics of LC and NLC during the COVID-19. A. SAI score of LC and NLC during the COVID-19 at baseline, uptrend period and downtrend period. B. CDT score of LC and NLC during the COVID19 at baseline, uptrend period and downtrend period. For detailed statistical analysis, see text and Table 3.

\section{Supplementary Files}

This is a list of supplementary files associated with this preprint. Click to download.

- eTable1.docx

- eTable2.docx

- eTable3.docx 